\title{
CSOH: LOW-TEMPERATURE HEAT CAPACITY AND HIGH-TEMPERATURE ENTHALPY INCREMENT
}

\author{
R. J. M. Konings, $\uparrow$ E. H. P. Cordfunke, $†$ E. F. Westrum, JR $\ddagger$ and R. Shaviv $\ddagger$ \\ †Netherlands Energy Research Foundation ECN, P.O. Box 1, 1755 ZG Petten, The Netherlands \\ $\ddagger$ Department of Chemistry, University of Michigan, Ann Arbor, MI 48104, U.S.A.
}

(Received 26 April 1989; accepted in revised form 3 January 1990)

\begin{abstract}
Abatract-- Heat capacities of $\mathrm{CsOH}(s)$ have been measured by adiabatic calorimetry from 5 to $350 \mathrm{~K}$, and a reversible $\lambda$-type transition has been observed at $233.96 \mathrm{~K} . C^{0}(298.15 \mathrm{~K})=(69.96 \pm 0.10) \mathrm{J} \mathrm{mol}^{-1} \mathrm{~K}^{-1}$ and $S^{\circ}(298.15 \mathrm{~K})=(104.22 \pm 0.08) \mathrm{J} \mathrm{mol}^{-1} \mathrm{~K}^{-1}$. High-temperature enthalpy increments of solid as well as liquid $\mathrm{CsOH}$ have been measured from 440 to $683 \mathrm{~K}$ by drop calorimetry. In combination with DSCmeasurements the orthorhombic/cubic transition and the melting point were located at $(498.2 \pm 0.5) \mathrm{K}$ and $(615.5 \pm 0.5) \mathrm{K}$, respectively.
\end{abstract}

Keywords: Cesium hydroxide, $\mathrm{CsOH}$, adiabatic calorimetry, drop calorimetry, phase transitions, thermodynamic properties, thermophysical properties.

\section{INTRODUCTION}

Although solid cesium hydroxide is included in the thermochemical compilations by the JANAF team [1] and Glushko et al. [2], the experimental basis for these assessments is rather poor. The enthalpy of formation has been derived from measurements made more than 80 years ago; heat-capacity measurements have not been reported. The tabulations are thus mainly based on estimated quantities. Because $\mathrm{CsOH}$ is of interest as a potential reaction product of the core-coolant interaction in LWR-reactor accidents, we made a systematic investigation of its thermochemical properties. In recent papers the vapour pressure, measured by transpiration technique [3], and a redetermination of the enthalpy of formation by solution calorimetry [4], were reported. The present paper completes our investigations of condensed CsOH: low-temperature heat capacities have been measured by adiabatic calorimetry and enthalpy increments for the solid as well as the liquid have been measured by drop calorimetry. Additional information on the high-temperature phase transitions has been obtained by DSC. From these data, smoothed thermodynamic functions have been calculated up to $1000 \mathrm{~K}$.

\section{EXPERIMENTAL}

The preparation of $\mathrm{CsOH}$ from cesium metal has been described before [4]. For the present study three different samples have been used whose chemical compositions are given in Table 1. Cesium was determined gravimetrically with kalignost; $\mathrm{CO}_{3}^{2-}$ was analysed by titration with $\mathrm{HCl}(a q)$.
For the low-temperature heat capacity measurements $21.4469 \mathrm{~g}$ of the $\mathrm{CsOH}-1$ sample was loaded into the gold-plated copper calorimeter (laboratory designation W-99) provided with a screw-type closure with a stainless-steel knife edge and an annealed gold gasket. The loaded calorimeter was evacuated and $2.7 \mathrm{kPa}$ of helium gas was added at $300 \mathrm{~K}$ to facilitate thermal contact between sample and calorimeter.

Heat-capacity measurements were made in the range $5-345 \mathrm{~K}$ in the Mark XIII adiabatic cryostat [5]. The calorimeter was surrounded by a shield system provided with automatic temperature control. A Leeds and Northrup capsule-type platinum-resistance thermometer (laboratory designation A-5) was used for temperature determinations. The thermometer was calibrated at the NBS against IPTS-1948 (as textually revised in 1960) [6] for temperatures above $90.2 \mathrm{~K}$, against the NBS provisional scale from 10 to $90 \mathrm{~K}$, and by the calibration technique of McCrackin and Chang [7] below $10 \mathrm{~K}$. These calibrations are judged to reproduce thermodynamic temperatures to within $0.03 \mathrm{~K}$ from 10 to $90 \mathrm{~K}$ and to within $0.04 \mathrm{~K}$ above $90 \mathrm{~K}$. Determinations of mass, current, voltage and time are referred to standardizations and calibrations performed at the NBS. The accuracy of a single heat-capacity measurement is considered to be about $0.5 \%$ from 10 to $15 \mathrm{~K}$ increasing to about $0.1 \%$ between 30 and $350 \mathrm{~K}$.

The enthalpy increments above $298.15 \mathrm{~K}$ were measured in an isothermal diphenyl ether calorimeter which has been described previously [8]. Briefly, the sample is enclosed in a spherical silver ampoule (15 ppm total metal impurity) with a $0.25 \mathrm{~mm}$ wall 
Table 1. Analytical results for $\mathrm{CsOH}$; mass fraction $w$

\begin{tabular}{|c|c|c|c|}
\hline \multicolumn{4}{|c|}{$10^{2} w(\mathrm{Cs})$} \\
\hline Sample code & Found & Calc. $\dagger$ & $10^{2} w \cdot\left(\mathrm{Cs}_{2} \mathrm{CO}_{3}\right)$ \\
\hline 1 & $88.41 \pm 0.06$ & 88.66 & 0.27 \\
\hline 2 & $88.63 \pm 0.05$ & 88.66 & $<0.02$ \\
\hline 3 & $88.68 \pm 0.03$ & 88.66 & $<0.02$ \\
\hline $\begin{array}{r}\text { tThe mola } \\
141.9127 \mathrm{~g} \mathrm{~mol}\end{array}$ & mass of & $\mathrm{CsOH}$ & taken \\
\hline
\end{tabular}

thickness, a $20 \mathrm{~mm}$ diameter and a volume of $3.8 \mathrm{~cm}^{3}$. The ampoule is heated in a furnace whose temperature is measured with calibrated $\mathrm{Pt}$ to $(\mathrm{Pt}+10$ mass \% $\mathrm{Rh})$ thermocouples to $\pm 0.1 \mathrm{~K}$. After thermal equilibration, the ampoule is dropped into the calorimeter. The energy of the ampoule plus the sample now melts solid diphenyl-ether in equilibrium with its liquid in a closed system. The resulting volume increase of the ether is determined by weighing the displaced mercury. The ratio of heat input to mass of mercury making up the volume change is a constant for the apparatus $\left(79.8973 \mathrm{~J} \mathrm{~g}^{-1}\right.$ ) and is obtained by calibration with the NBS standard reference material (No. 720) synthetic sapphire, $\mathrm{Al}_{2} \mathrm{O}_{3}$. The enthalpy contributions of silver have been determined separately and are reported elsewhere [9].

The drop calorimetric measurements were made in two series. For the first series $7.81521 \mathrm{~g} \mathrm{CsOH}-2$ was enclosed in an ampoule of $4.01356 \mathrm{~g}$. For the second series the weights were $4.90927 \mathrm{~g}$ of $\mathrm{CsOH}-3$ and $3.86517 \mathrm{~g}$, respectively. All masses were corrected for weighing in argon to masses in vacuum. A correction was made to account for the difference in enthalpy between the final calorimeter temperature $(300.06 \mathrm{~K})$ and the standard reference temperature, $298.15 \mathrm{~K}$, using $C_{p}^{0}(298.15 \mathrm{~K})$.

The transition temperatures for $\mathrm{CsOH}$ were recorded directly in a Mettler DSC apparatus (type TA-13) by heating $\mathrm{CsOH}$ in a sealed silver crucible at a heating rate of $5 \mathrm{~K} \mathrm{~min}^{-1}$, using the melting points of $\mathrm{Sn}$ and $\mathrm{Zn}$ as reference. The temperatures were recorded as onset values; the indicated uncertainty is the standard deviation of a number of DSC runs.

\section{RESULTS}

The results of the low-temperature heat capacity measurements are given in Table 2 ; the indi-

Table 2. Experimental low-temperature heat capacities of $\mathrm{CsOH}$ in

\begin{tabular}{|c|c|c|c|c|c|}
\hline$T(\mathrm{~K})$ & $C_{p}^{0}$ & $T(\mathbf{K})$ & $C_{p}^{0}$ & $T(\mathrm{~K})$ & $C_{p}^{0}$ \\
\hline \multicolumn{2}{|c|}{ Series I } & 76.49 & 36.23 & 279.36 & 70.02 \\
\hline 5.63 & 0.172 & 80.95 & 37.42 & 286.62 & 69.95 \\
\hline 6.20 & 0.250 & 85.42 & 38.51 & 293.88 & 69.91 \\
\hline 6.86 & 0.380 & 90.17 & 39.55 & 301.14 & 69.95 \\
\hline 7.55 & 0.563 & 95.20 & 40.50 & 308.37 & 70.05 \\
\hline 8.28 & 0.805 & 100.23 & 41.37 & 315.60 & 70.30 \\
\hline 9.13 & 1.137 & 105.27 & 42.22 & 322.82 & 70.58 \\
\hline 10.12 & 1.586 & 110.33 & 43.05 & 330.06 & 70.84 \\
\hline 11.11 & 2.115 & 115.40 & 43.86 & 337.29 & 71.07 \\
\hline 12.13 & 2.724 & 120.49 & 44.65 & 344.04 & 71.32 \\
\hline 13.30 & 3.519 & 125.83 & 45.43 & \multicolumn{2}{|c|}{ Series II } \\
\hline 14.60 & 4.469 & 131.42 & 46.24 & 219.22 & 65.03 \\
\hline 15.93 & 5.489 & 137.03 & 47.02 & 221.25 & 66.52 \\
\hline 17.30 & 6.563 & 142.64 & 47.77 & 223.24 & 68.17 \\
\hline 18.70 & 7.660 & 144.81 & 48.04 & 225.28 & 70.62 \\
\hline 20.12 & 8.776 & 148.29 & 48.52 & 227.36 & 73.80 \\
\hline 21.57 & 9.892 & 150.68 & 48.82 & 228.88 & 76.70 \\
\hline 23.04 & 11.00 & 156.81 & 49.67 & 229.87 & 78.48 \\
\hline 24.79 & 12.28 & 162.95 & 50.53 & 230.84 & 82.87 \\
\hline 26.80 & 13.71 & 169.09 & 51.42 & 231.79 & 85.90 \\
\hline 28.83 & 15.09 & 175.23 & 52.37 & 232.70 & 90.91 \\
\hline 31.05 & 16.57 & 181.63 & 53.44 & 233.58 & 96.78 \\
\hline 33.47 & 18.11 & 188.28 & 54.63 & 234.45 & 92.80 \\
\hline 35.90 & 19.58 & 194.93 & 55.97 & 235.38 & 80.27 \\
\hline 38.53 & 21.10 & 201.56 & 57.61 & 236.36 & 76.25 \\
\hline 41.36 & 22.63 & 208.18 & 59.66 & 237.37 & 74.43 \\
\hline 44.21 & 24.11 & 214.77 & 62.39 & 238.39 & 73.16 \\
\hline 46.71 & 25.36 & 221.54 & 66.73 & 239.41 & 72.80 \\
\hline 49.63 & 26.75 & 228.39 & 76.40 & 240.92 & 72.41 \\
\hline 53.01 & 28.25 & 235.16 & 84.35 & 242.92 & 71.96 \\
\hline 56.39 & 29.66 & 242.57 & 72.06 & 244.92 & 71.46 \\
\hline 60.03 & 31.07 & 250.22 & 71.01 & 246.93 & 71.06 \\
\hline 63.93 & 32.46 & 257.53 & 70.56 & 248.94 & 71.02 \\
\hline 67.85 & 33.74 & 264.81 & 70.27 & \multicolumn{2}{|c|}{ Series III } \\
\hline 72.04 & 34.99 & 272.09 & 70.10 & 221.41 & 66.65 \\
\hline & & & & 249.10 & 71.09 \\
\hline
\end{tabular}




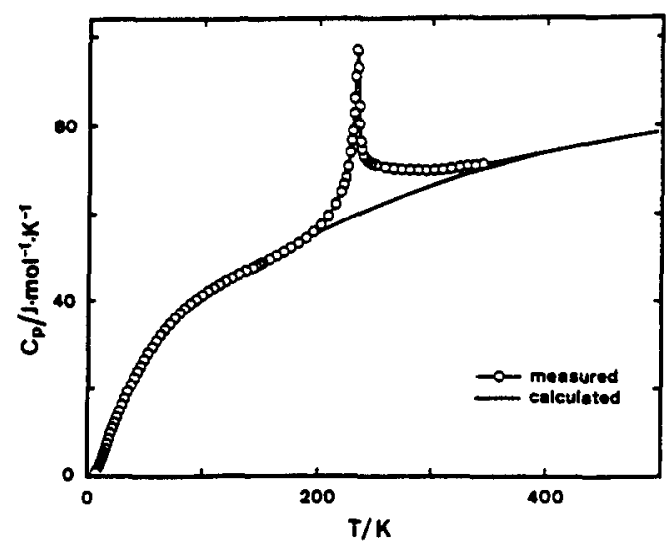

Fig. 1. The low-temperature heat capacity of $\mathrm{CsOH}$.

vidual measurements are plotted in Fig. $I$ as a function of temperature. The data were fitted to a power series in orthogonal polynomials as described by Justice [10], from which the smoothed thermodynamic functions in Table 3 were calculated: $C_{p}^{0}(298.15 \mathrm{~K})=(69.96 \pm 0.10) \mathrm{J} \mathrm{mol}^{-1} \mathrm{~K}^{-1}$, and $S^{0}(298.15 \mathrm{~K})=(104.22 \pm 0.08) \mathrm{J} \mathrm{mol}^{-1} \mathrm{~K}^{-1}$.

A reversible $\lambda$-type transition with a peak maximum of $233.96 \mathrm{~K}$ was observed in the heat capacity of $\mathrm{CsOH}$. The extension of the excess contribution is very broad, ranging from 190 to about $400 \mathrm{~K}$. The enthalpy and entropy of transition were calculated from the excess heat capacity which was obtained by subtracting the lattice heat capacity from the experimental results.
The contribution of the lattice was determined from the single parameter phonon distribution lattice fitting theory of Komada and Westrum [11] yielding $\theta_{\mathrm{kw}}=143.5$. This fitting procedure allows for acoustic as well as optical modes and can therefore be used at high temperatures. We thus obtain $\Delta_{\mathrm{ts}} H^{0}=958 \mathrm{~mol}^{-1} \quad(=115.2 \mathrm{R})$ and $\Delta_{\mathrm{trs}} S^{0}=4.095 \mathrm{~J} \mathrm{~mol}^{-1} \mathrm{~K}^{-1}(=0.492 \mathrm{R})$.

The results of the 27 drop calorimetric measurements are given in Table 4, and are plotted in Fig. 2. Two discontinuities have been observed: the solid state orthorhombic/cubic transformation and the melting point (see Discussion). The data have been fitted to three polynomial equations. For the orthorhombic phase we obtained:

$$
\begin{array}{r}
\left\{H^{0}(T)-H^{0}(298.15 \mathrm{~K})\right\} / \mathrm{J} \mathrm{mol}^{-1}=57.8256(T / \mathrm{K}) \\
+20.3495 \cdot 10^{-3}(T / \mathrm{K})^{2}-19049.6
\end{array}
$$

applying $C_{p}^{0}(T)=69.96 \mathrm{~J} \mathrm{~mol}^{-1} \mathrm{~K}^{-1}$ and $\left\{H^{0}(T)-\right.$ $\left.H^{0}(298.15 \mathrm{~K})\right\}=0$ at $T=298.15 \mathrm{~K}$ as boundary conditions. This function joins smoothly the lowtemperature data discussed above. For the cubic phase we obtained:

$$
\begin{aligned}
\left\{H^{0}(T)-H^{0}(298.15 \mathrm{~K})\right\} / \mathrm{J} \mathrm{mol}-1 & \\
= & 72.676(T / \mathrm{K})-15997.7
\end{aligned}
$$

\begin{tabular}{|c|c|c|c|}
\hline \multicolumn{4}{|c|}{$H^{0}(T)-H^{0}(298.15 \mathrm{~K})$}$\left.(\mathrm{J} \mathrm{mol})^{-1}\right)$ \\
\hline$T(\mathrm{~K})$ & Exp. & Calc. & $\delta(\%)$ \\
\hline 439.5 & 10305 & 10295 & 0.09 \\
\hline 449.3 & 11033 & 11039 & -0.06 \\
\hline 458.9 & 11774 & 11772 & 0.02 \\
\hline 468.4 & 12474 & 12501 & -0.21 \\
\hline 478.5 & 13268 & 13279 & -0.18 \\
\hline 488.3 & 14074 & 14039 & 0.25 \\
\hline 498.2 & 14810 & - & - \\
\hline 508.0 & 20999 & 20922 & 0.37 \\
\hline 517.8 & 21605 & 21634 & -0.13 \\
\hline 527.8 & 22394 & 22361 & 0.15 \\
\hline 537.8 & 23019 & 23087 & -0.30 \\
\hline 547.5 & 23789 & 23792 & -0.01 \\
\hline 558.4 & 24628 & 24585 & 0.17 \\
\hline 567.9 & 25149 & 25275 & -0.50 \\
\hline 573.2 & 25620 & 25660 & -0.16 \\
\hline 582.4 & 26350 & 26329 & 0.08 \\
\hline 588.3 & 26756 & 26758 & -0.01 \\
\hline 597.7 & 27533 & 27441 & 0.33 \\
\hline 622.8 & 36995 & 37188 & -0.39 \\
\hline 626.3 & 37569 & 37436 & 0.35 \\
\hline 633.1 & 38060 & 38014 & 0.12 \\
\hline 643.5 & 38994 & 38898 & 0.25 \\
\hline 653.4 & 39643 & 39740 & -0.24 \\
\hline 663.4 & 40478 & 40590 & -0.28 \\
\hline 673.5 & 41492 & 41449 & 0.10 \\
\hline 678.7 & 41829 & 41891 & -0.15 \\
\hline 683.4 & 42389 & $4229 !$ & 0.23 \\
\hline
\end{tabular}

Table 3. Experimental enthalpy increments of $\mathrm{CsOH}$ 
Table 4. Thermophysical functions of $\mathrm{CsOH}$ from 5 to $340 \mathrm{~K}$

\begin{tabular}{|c|c|c|c|c|}
\hline $\begin{array}{c}T \\
(\mathrm{~K})\end{array}$ & $\begin{array}{c}C_{-1}^{0} \\
\left(J \mathrm{~mol}^{-1} \mathrm{~K}^{-1}\right)\end{array}$ & $\begin{array}{c}S^{0} \\
\left(\mathrm{~J} \mathrm{~mol}^{-1} \mathrm{~K}^{-1}\right)\end{array}$ & $\begin{array}{c}-\left\{G^{0}(T)-H^{0}(0 \mathrm{~K})\right\} / T \\
\left(\mathrm{~J} \mathrm{~mol}^{-1} \mathrm{~K}^{-1}\right)\end{array}$ & $\begin{array}{c}H^{0}(T)-H^{0}(0 \mathrm{~K}) \\
(\mathrm{Jmol}-1)\end{array}$ \\
\hline 5 & $(0.125)$ & $(0.058)$ & $(0.025)$ & $(0.158)$ \\
\hline 10 & 1.513 & 0.449 & 0.108 & 3.376 \\
\hline 15 & 4.773 & 1.638 & 0.399 & 18.53 \\
\hline 20 & 8.680 & 3.542 & 0.931 & 52.14 \\
\hline 25 & 12.43 & 5.887 & 1.688 & 105.1 \\
\hline 30 & 15.88 & 8.464 & 2.592 & 176.0 \\
\hline 40 & 21.90 & 13,89 & 4.739 & 365.9 \\
\hline 50 & 26.92 & 19.32 & 7.109 & 610.6 \\
\hline 60 & 31.04 & 24.61 & 9.595 & 901.2 \\
\hline 70 & 34.40 & 29.66 & 12.10 & 1228.9 \\
\hline 80 & 37.19 & 34.44 & 17.05 & 1587.3 \\
\hline 100 & 41.36 & 43.22 & 19.46 & 2375.5 \\
\hline 120 & 44.56 & 51.04 & 24.09 & 3235.3 \\
\hline 140 & 47.42 & 58.14 & 28.45 & 4155.5 \\
\hline 160 & 50.10 & 64.64 & 32.57 & 5130.9 \\
\hline 180 & 53.15 & 70.71 & 36.48 & 6161.9 \\
\hline 200 & 57.19 & 76.50 & 40.19 & 7262.7 \\
\hline 220 & 65.55 & 82.28 & 46.78 & 8475.8 \\
\hline 240 & 72.38 & 88.87 & 47.17 & 10007.3 \\
\hline 260 & 70.51 & 94.63 & 50.67 & 11430.0 \\
\hline 280 & 69.97 & 99.83 & 54.00 & 12833.5 \\
\hline 300 & 69.97 & 104.65 & 57.22 & 14231.9 \\
\hline 320 & 70.43 & 109.19 & 60.32 & 15634.6 \\
\hline 340 & 71.17 & 113.48 & 63.32 & 17051.4 \\
\hline 273.15 & 70.05 & 98.09 & 52.87 & 12353.7 \\
\hline 298.15 & 69.96 & 104.22 & 56.92 & 14103.1 \\
\hline
\end{tabular}

and for the liquid phase:

$$
\begin{aligned}
\left\{H^{0}(T)-H^{0}(298.15 \mathrm{~K})\right\} / \mathrm{J} \mathrm{mol}^{-1} & \\
& =85.027(T / \mathrm{K})-15816.7
\end{aligned}
$$

The orthorhombic/cubic phase transition and the meiting point are obtained in DSC runs as

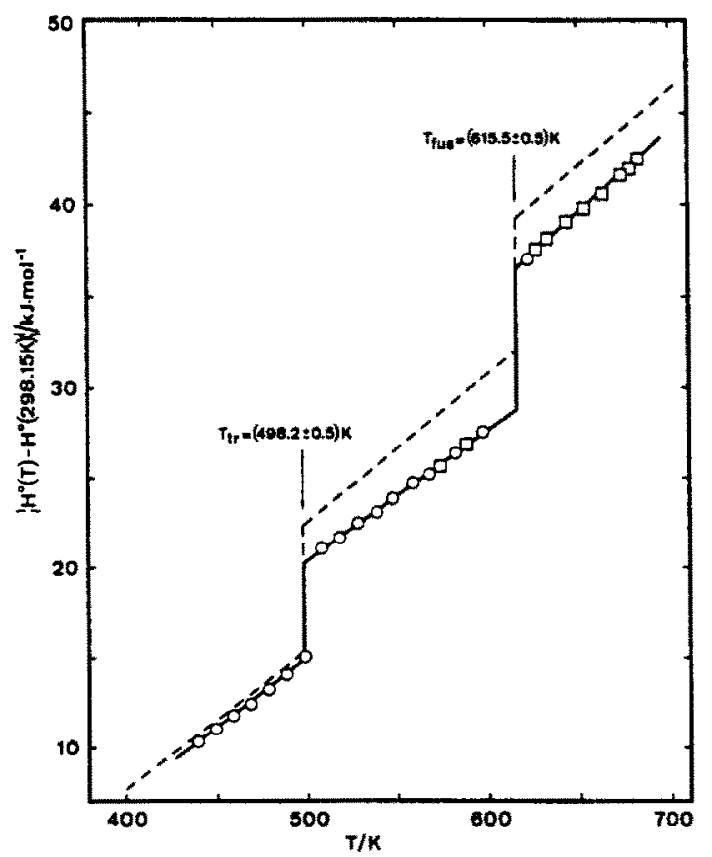

Fig. 2. The high-temperature enthalpy increments of $\mathrm{CsOH}$. sharp and reproducible peaks, and are located at $(498.2 \pm 0.5) \mathrm{K}$ and $(615.5 \pm 0.5) \mathrm{K}$, respectively. The enthalpy changes associated with these transitions have been calculated from the three equations above as $\Delta_{\text {trs }} H^{0}(498.2 \mathrm{~K})=5400 \mathrm{~J} \mathrm{~mol}^{-1}$ and $\Delta_{\text {fus }} H^{0}(615.5 \mathrm{~K})=7783 \mathrm{~J} \mathrm{~mol}^{-1}$.

The smoothed thermochemical functions above room temperature are listed in Table 5 . The enthalpy of formation of CsOH(s) was taken from Ref. 4, and the reference states of the elements from Glushko et al. [2],

\section{DISCUSSION}

The polymorphism of $\mathrm{CsOH}$ has been studied by Jacobs et al. [12-15] who used DSC, infrared/Raman spectroscopic, X-ray, and neutron diffraction techniques by Bastow et al. [16], who employed DTA, dielectric constant, and neutron diffraction measurements and by Haas and Schindewolf [17] using electrical conductivity measurements. These studies established three polymorphs of $\mathrm{CsOH}$ : an orthorhombic low-temperature modification (LTM), an orthorhombic room-temperature modification (RTM), and a cubic high-temperature modification (HTM). Amm et al. [18] also observed these modifcations in CsOD.

In their earlier work Jacobs et al. [12] reported the low-temperature phase transformation at about $232 \mathrm{~K}$ by $\mathrm{DSC}$, in good agreement with the present results. Their initial spectroscopic study [14] indicated different structural features: weak hydrogen bonds being present in the LTM and absent in the RTM. 
Table 5. The thermal properties in $\mathrm{CsOH}$ transformations

\begin{tabular}{llcc}
\hline$T(\mathrm{~K})$ & Nature & $\Delta_{\mathrm{ts}} H^{0}\left(\mathrm{~J} \mathrm{~mol}^{-1}\right)$ & $\Delta_{\mathrm{ts}} S^{0}\left(\mathrm{~J} \mathrm{~mol}^{-1} \mathrm{~K}^{-1}\right)$ \\
\hline 233.96 & Ferroelectric & 958 & 4.095 \\
498.2 & Orthorhombic/cubic & 5400 & 10.84 \\
615.5 & Fusion & 7783 & 12.65 \\
\hline
\end{tabular}

The more recent DSC-results by Jacobs et al. [13] do not show the transformation, which is supported by a study of the temperature shift of the OD stretching frequency in isotopically diluted $\mathrm{CsOH}$ [15]. However, the authors do not comment on this discrepancy.

The low-temperature transition was located by Bastow et al. at $232 \mathrm{~K}$, who found the LTM to be anti-ferroelectrically ordered. They concluded that the phase transformation in $\mathrm{CsOH}$ probably involves coherent tunneling of $H \mathrm{~s}$ to reverse the polarities of chains of oxygen atoms linked by weak hydrogen bonds. Amm et al. [18] concluded from a NMR study of CsOD that reorientational motion of the OD ion occurs in the RTM but not in the LTM.

From the similarity with the low-temperature transformations in $\mathrm{KOH}$ and $\mathrm{KOD}$ [19], and especially $\mathrm{NaOD}$ [20], which was explored by lowtemperature X-ray diffraction, Bastow et al. sug. gested the transition in $\mathrm{CsOH}$ to be first order. However, a comparison of recent low-temperature heat capacity data for $\mathrm{KOH}$ and KOD by White et al. [21] and NaOD by White and Moore [22] with the present data for $\mathrm{CsOH}$, shows a distinct difference. The transitions in $\mathrm{KOH}, \mathrm{KOD}$ and $\mathrm{NaOD}$ are sharp, the widths being 10,21 and $18 \mathrm{~K}$, respectively. White calculated the excess heat capacity assuming a discontinuity of the lattice heat capacity (first order), and obtained $\Delta_{\mathrm{trs}} S=$ $0.121 \mathrm{R}, 0.126 \mathrm{R}$ and $0.103 \mathrm{R}$, respectively. In contrast, the width of the transition in $\mathrm{CsOH}$ is very broad, about $210 \mathrm{~K}$, indicating a non-isothermal effect, and since the high-temperature data fit the same $\theta_{\mathrm{Kw}}$ as the low-temperature data, our approach of continuity of the lattice heat capacity through the transition (second order) therefore seems correct. The entropy of transition in $\mathrm{CsOH}$ calculated in this way, $\Delta_{\mathrm{tn}} S=0.492 \mathrm{R}$, is significantly higher than in $\mathrm{KOH}, \mathrm{KOD}$ and $\mathrm{NaOD}$. In case the phase transformation is assumed to be solely the results of independent ordering of the dipoles, the theoretical value of $\Delta_{\mathrm{trs}} S$ would be $R \ln 2$ (=0.693R).

The values for the temperatures of the orthorhombic-to-cubic and the cubic-to-liquid transitions presented here, $(498.2 \pm 0.5) \mathrm{K}$ and $(615.5 \pm 0.5) \mathrm{K}$, respectively, are in fair agreement with previous data. Cohen-Adad and Ruby [23] reported 488 and $619 \mathrm{~K}$, Reshetnikov and Baranskaya [24] 493 and $588 \mathrm{~K}$, and Jacobs et al. [12,13] 497.5 and $612 \mathrm{~K}$, respectively. In addition, Jacobs and Harbrecht [12] as well as Reshetnikov and Baranskaya [24] reported a thermal effect around $410 \mathrm{~K}$, which was not observed in the present study. This effect is probably due to the loss of some residual water [25]. The values for the enthalpies associated with these transitions are, however, in poor agreement. Reshetnikov and Baranskaya [24] obtained 6070 and $4560 \mathrm{~J} \mathrm{~mol}^{-1}$ and Jacobs et al. $[12,13] 7120$ and $7400 \mathrm{~J} \mathrm{~mol}^{-1}$, respectively, compared with 5400 and $7783 \mathrm{~J} \mathrm{~mol}^{-1}$, as obtained in this study.

The present thermodynamic data for $\mathrm{CsOH}$ deviate considerably from the DSC results of Jacobs et al. Apart from the absence of the low-temperature transition in the data of Jacobs et al., the present data suggest a constant $C_{p}$ for the RTM and HTM, whereas the data of Jacobs et al. show a strong temperature dependence. This may be attributed to the presence of carbonate or water impurities and the use of the inherently less accurate DSC technique.

Table 6. Thermodynamic functions of $\mathrm{CsOH}(s, l)$

\begin{tabular}{lcccccc}
\hline $\begin{array}{c}T \\
(\mathrm{~K})\end{array}$ & $\begin{array}{c}C^{0} \\
\left(\mathrm{~J} \mathrm{~mol}^{-1} \mathrm{~K}^{-1}\right)\end{array}$ & $\begin{array}{c}S^{0} \\
\left(\mathrm{~J} \mathrm{~mol}^{-1} \mathrm{~K}^{-1}\right)\end{array}$ & $\begin{array}{c}-\left\{G^{0}-H^{0}(298)\right\} / T \\
\left(\mathrm{~J} \mathrm{~mol}^{-1} \mathrm{~K}^{-1}\right)\end{array}$ & $\begin{array}{c}\left\{H^{0}-H^{0}(298.15 \mathrm{~K})\right\} \\
\left(\mathrm{J} \mathrm{mol}^{-1}\right)\end{array}$ & $\begin{array}{c}\Delta_{f} H^{0}(T) \\
\left(\mathrm{J} \mathrm{mol}^{-1}\right)\end{array}$ & $\begin{array}{c}\Delta_{f} G^{0}(T) \\
\left(\mathrm{J} \mathrm{mol}^{-1}\right)\end{array}$ \\
\hline 298.15 & 69.960 & 104.220 & 104.220 & 0 & -416440 & -372072 \\
300 & 70.035 & 104.653 & 104.221 & 130 & -416424 & -371797 \\
400 & 74.104 & 125.358 & 107.017 & 7337 & -417492 & -356380 \\
498.2 & 78.102 & 142.050 & 112.323 & 14810 & -416048 & -341543 \\
498.2 & 72.676 & 152.889 & 112.323 & 20209 & -410648 & -341543 \\
500 & 72.676 & 153.511 & 112.470 & 20340 & -410629 & -341282 \\
600 & 72.676 & 166.401 & 120.338 & 27608 & -409452 & -327523 \\
615.5 & 72.676 & 168.255 & 121.570 & 28734 & -409264 & -325468 \\
615.5 & 85.027 & 180.900 & 121.570 & 36517 & -401481 & -325468 \\
700 & 85.027 & 191.838 & 129.407 & 43702 & -399419 & -315101 \\
800 & 85.027 & 203.192 & 137.936 & 52205 & -396981 & -303221 \\
900 & 85.027 & 213.207 & 145.754 & 60708 & -394586 & -291646 \\
1000 & 85.027 & 222.165 & 152.955 & 69210 & -460011 & -276745 \\
\hline
\end{tabular}




\section{REFERENCES}

1. Chase M. W. et al., JANAF Thermochemical Tables, 3rd Edition. J. phys. Chem. Ref. Data 14, Suppl. 1 (1978-82)

2. Glushko V. P. et al., Termodinamicheskie Svoistva Individual'nykh Veshchestv. Tom IV. Nauk. Moskva (1978-1982).

3. Konings R. J. M. and Cordfunke E. H. P., J. Chem. Thermodynam. 20, 103 (1988).

4. Konings R. J. M., Cordfunke E. H. P. and Ouweltjes W., J. Chem. Thermodynam. 20, 777 (1988).

5. Westrum E. F., Jr, Furukawa G. T. and McCullough J. P., in Experimental Thermodynamics Vol. I. (Edited by D. W. Scott and J. P. McCullough). Butterworths (1968).

6. Stimson H. F., J. Res. natn. Bur. Stand. 65A, 139 (1961).

7. McCrackin F. L. and Change S. S., Rev. scient. Instrum. 46, 550 (1975).

8. Cordfunke E. H. P., Muis R. P., and Prins G., J. Chem. Thermodynam. 11, 819 (1979).

9. Cordfunke E. H.P. and Konings R. J. M., Thermochim Acta 157, 315 (1989).

10. Justice B. H., Thermal data fitting with orthogonal functions and combined table generation. The FITAB program project report COO-1149-143. February 1969. Department of Chemistry, The University of Michigan, Ann Arbor.
11. Komada N. and Westrum E. F., Jr, J. Chem. Thermodynam. (submitted).

12. Jacobs H. and Harbrecht B., Z. Naturf. 36B, 270 (1981).

13. Jacobs H., Mach B., Harbrecht B., Lutz H. D. and Henning J. A., Z. anorg. allg. Chem. S44, 55 (1987).

14. Lutz H. D., Henning J., Jacobs H. and Mach B., J. molec. Struct. 145, 277 (1986).

15. Henning J., Lutz H. D., Jacobs H. and Mach B., J. molec. Struct. 196, 113 (1989).

16. Bastow T. J., Elcombe M. M. and Howard C. J., Solid St. Commun. 62, 149 (1987).

17. Haas K. H. and Schindewolf U., Ber. Bunsenges. Phys. Chem. 87, 346 (1983).

18. Amm D. T., Segel S. L. and Jeffrey K. R., Can. J. Phys. 64, 22 (1986).

19. Bastow T. J., Elcombe M. M. and Howard C. J., Solid St. Commun. 57, 339 (1986).

20. Bastow T. J., Elcombe M. M. and Howard C. J., Solid St. Commun. 59, 257 (1986).

21. White M. A., Perrot A., Britte D. and Oort M. J. M. van, J. chem. Phys. 89, 4346 (1988).

22. White M. A. and Moore S. A., J. chem. Phys. 85, 4629 (1986).

23. Cohen-Adad M. M. and Ruby C., Compt. rend (Paris) 258, 6163 (1964).

24. Reshetnikov N. A. and Baranskaya E. V., Itv. Vyssh. Ucheb. Zaved. Khim. Khim. Teknol. 10, 196 (1967).

25. Johansson L. G. and Kazikowski S., Report LACETR-072. 